\title{
Long-term effects of growth hormone replacement therapy in childhood-onset craniopharyngioma: results of the German Craniopharyngioma Registry (HIT-Endo)
}

\author{
Svenja Boekhoff1, Agnieszka Bogusz ${ }^{1,2}$, Anthe S Sterkenburg ${ }^{1,3}$, Maria Eveslage ${ }^{4}$ and \\ Hermann L Müller ${ }^{1}$ \\ ${ }^{1}$ Department of Pediatrics and Pediatric Hematology/Oncology, Klinikum Oldenburg AöR, Medical Campus \\ University Oldenburg, Oldenburg, Germany, ${ }^{2}$ Department of Endocrinology and Diabetology, The Children's \\ Memorial Health Institute, Warsaw, Poland, ${ }^{3}$ Department of Surgery, University Hospital, Heidelberg, Germany, and \\ ${ }^{4}$ Institute of Biostatistics and Clinical Research, University of Münster, Münster, Germany
}

Correspondence should be addressed to $\mathrm{H}$ L Müller

Email

mueller.hermann@

klinikum-oldenburg.de

\begin{abstract}
Objective: Quality of survival, prognosis and long-term outcome are often severely impaired in childhood-onset craniopharyngioma (CP) patients. Identification of risk factors for sequelae such as growth hormone (GH) deficiency is important for appropriate treatment and rehabilitation.

Design: In a cross-sectional study, 79 CP patients recruited in HIT-Endo before 2000 were analyzed according to GH substitution: (a) CP never GH treated (noGH); (b) CP GH treated only during childhood (pedGH); (c) CP under GH, initiated at adulthood (adultGH); (d) CP under GH during childhood and continued during adulthood (contGH). Methods: Progression-free (PFS) and overall survival (OS), height, BMI, psychosocial and neuropsychological status (EORTC QLQ-C30, MFI-20).

Results: OS and PFS rates were similar in all subgroups. ContGH and pedGH CP presented with increases in height $(P=0.002 ; P=0.0001)$ during long-term follow-up when compared with baseline. In all subgroups except for pedGH, increases in BMI were observed when compared with BMI at diagnosis. For emotional functionality and physical fatigue, adultGH CP showed worse $(P=0.037 ; P=0.034)$ response (mean: $61.4 \% ; 12.5 \%)$ when compared with pedGH CP (mean: $83.5 \% ; 7.7 \%$ ). Observed differences were not related to irradiation and hypothalamic involvement. In terms of psychosocial status, no differences were observed between subgroups.

Conclusions: We conclude that GH substitution was safe with regard to risk of tumor progression/relapse in CP. Growth was improved by GH, whereas the development of obesity was not influenced by GH substitution. However, early initiation of GH substitution after CP diagnosis might have beneficial effects on weight development and neuropsychological outcome.
\end{abstract}

\section{Introduction}

Childhood-onset craniopharyngioma (CP) is a rare embryonic tumor, arising from remnants of Rathke pouch $(1,2)$. Although the tumor typically presents with histological signs of low-grade malignancy (WHO grade 1) and overall survival is high in CP patients, quality of survival (QoS) is frequently reduced due to considerable morbidity $(3,4)$. QoS and long-term outcome in survivors of $\mathrm{CP}$ are severely reduced due to hormonal deficits that 
typically result in obesity and stunted growth $(5,6)$. Furthermore, hypothalamic involvement (HI) and surgical lesions of hypothalamic structures cause considerable QoS impairments $(7,8,9,10)$. Growth hormone (GH) substitution has been safely and successfully used to treat and/or prevent short stature in childhood cancer survivors and CP patients $(11,12,13,14)$. The impact of GH substitution therapy on psychosocial status, QoS, weight and height, in long-term survivors of CP patients is not well characterized.

Because prospective studies analyzing impact of GH substitution on QoS in CP patients do not exist, QoS, weight development and growth of $\mathrm{CP}$ patients recruited in the German Craniopharyngioma Registry were evaluated with regard to age at initiation, dosage and duration of GH replacement therapy (15).

\section{Subjects and methods}

\section{Patients}

We analyzed history before CP diagnosis in 280 childhood-onset CP patients, diagnosed between 1966 and 2000, registered in the German Craniopharyngioma Registry (NCT00258453; NCT01272622) and recruited in our prospective multicenter trial HIT-Endo and KRANIOPHARYNGEOM 2000/2007 (16). HIT-Endo trial data include data on physical condition, auxiological parameters and an evaluation of the patient's records for history, clinical manifestations, imaging results, operative strategies, irradiation (dosage, age at initiation) and treatment period of GH substitution therapy. In all cases included in our cross-sectional study, the histological diagnosis of adamantinomatous CP was confirmed by neuropathological reference assessment. HI was reference assessed by a neuroradiologist blinded for clinical databased CT, MRI and/or neurosurgical intraoperative inspection. HI was assumed when involvement of hypothalamic structures either by $\mathrm{CP}$ growth into hypothalamus or displacement of hypothalamic structures by CP. Tumor size was calculated using maximal tumor diameters in two dimensions based on reference assessment of neuroradiological imaging.

In our cross-sectional study, we were able to analyze prognoses in 261 of 280 (93\%) long-term survivors of CP with a minimum of 10-year follow-up (16). Four questionnaires were mailed to 93 patients for whom current postal addresses were available, to collect data on current height and body weight, GH substitution, psychosocial and neuropsychological status, and physical and mental fatigue. Seventy-nine of 93 (85\%) patients answered the questionnaires. Long-term survivors after $\mathrm{CP}$, eligible for study participation, were analyzed according to GH substitution in four subgroups: (a) patients, who never received GH substitution (noGH), (b) patients, who received GH substitution only during childhood and did not continue during adulthood (pedGH), (c) patients, who started GH substitution at adulthood after not having received GH substitution therapy during childhood (adultGH), and (d) patients, who started GH substitution during childhood and continued after reaching adult age i.e. these patients presented under $\mathrm{GH}$ substitution at time of study (contGH). All CP showed clinical symptoms (reduced growth velocity and/or short stature) and laboratory findings indicative for $\mathrm{GH}$ deficiency after $\mathrm{CP}$ diagnosis i.e. pathological findings ( $\mathrm{GH}<8.0 \mathrm{ng} / \mathrm{mL}$ ) in two stimulating tests. Time point of initiation and duration of GH substitution therapy were based on decision of local treating physicians.

The study was approved by the local standingcommittee on ethical practice of Medizinische Fakultät, Julius-Maximilians-Universität Würzburg, Germany (approval: 94/06), and written parental and/or patient consent was obtained in all cases. All procedures performed in our study were in accordance with the ethical standards of the institutional and/or national research committee and with the 1964 Helsinki Declaration and its later amendments or comparable ethical standards.

\section{Auxiological data}

Height and weight were analyzed based on measurements performed by clinicians participating in HIT-Endo at three time points: at CP diagnosis, $8-12$ years after CP diagnosis, and during long-term follow-up i.e. $>12$ years after CP diagnosis. Height was evaluated by calculating height SDS according to references of Prader et al. (17). The degree of obesity was analyzed by calculating the BMI SDS according to references of Rolland-Cachera et al. (18).

\section{Questionnaires}

The EORTC QLQ-C30 questionnaire measures healthrelated QoS in cancer survivors and consists of single-item measures and multi-item scales, including three symptom scales, five functional scales, a global QoS/health status scale and six single items (19). The scores of the single items and scales are assessed as percentages. A 100\% score refers to the highest item response; a $0 \%$ score of represents no response. Global health status and functional scales 
are scored positively; the higher the percentage, the better global health status and functioning. Symptom scales are scored negatively; the higher the percentage, the more symptoms are observed (19).

The MFI-20 questionnaire quantifies fatigue in five dimensions: general fatigue, mental fatigue, reduced activity, physical fatigue and reduced motivation. MFI-20 domains are assessed by 20 questions, which are scored on a likert scale ranging from 1 to 5 . Each of the five MFI-20 domains represent a score ranging from 4 to 20; the higher the score, the more response for the respective domain and the more fatigue the patient is observed to experience (20).

In adult long-term CP survivors aged $>20$ years at the time of study, a newly designed questionnaire was used to assess psychosocial status (10).

\section{Statistical analyses}

Statistical analysis was performed using SPSS 19.0 (SPSS, Inc.). Mann-Whitney $U$ test was used for comparison of continuous variables between two independent groups and Wilcoxon signed-rank test was used for comparison of two related groups for continuous variables. Chisquare test was used for comparison of different groups for categorical variables. Progression-free survival (PFS) and overall survival (OS) rates were estimated by KaplanMeier analyses. Events for estimation of PFS were defined as neuroradiologically confirmed $>20 \%$ progression of residual tumor, reference-confirmed tumor recurrence after reference-confirmed complete surgical resection and death. Inferential statistics are intended to be exploratory (hypotheses generating), not confirmatory, and are interpreted accordingly. The local significance level is set to 0.05 , i.e. $P$ values of $\leq 0.05$ were considered statistically significant. No adjustment for multiple testing was applied.

\section{Results}

\section{Long-term outcome and survival rates}

Childhood-onset CP patients $(n=280)$ diagnosed between 1966 and 2000 were registered in the German Craniopharyngioma Registry and analyzed prospectively in themulticenterstudiesHIT-EndoandKRANIOPHARYNGEOM 2000/2007 (16). Long-term outcome with regard to GH substitution could be analyzed in 79 (28\%) of these patients. The questionnaires used to analyze GH substitution therapy in patient history and the current height and body weight, QoS and psychosocial status of long-term survivors recruited in HIT-Endo were mailed at least 9.8 years after CP diagnosis to 93 of 280 patients (33\%); $79 \mathrm{CP}$ patients (85\%) responded and $14 \mathrm{CP}$ patients (15\%) did not. No differences in terms of gender, age at CP diagnosis, BMI SDS, follow-up interval, degree of surgical resection and $\mathrm{HI}$ were observed between the participating group of $\mathrm{CP}$ patients and the group of $\mathrm{CP}$ patients not responding to the mailing and therefore not participating in our study (data not shown).

Patient characteristics and auxiological data of 79 participating CP patients (36 males, 43 females) are depicted in Table 1. Median age at the time of diagnosis was 9.2 years. Median time interval between CP diagnosis and study was 15.9 years, ranging from 9.8 to 33.8 years. Median age at evaluation was 31 years, ranging from 20 to 48 years. The median BMI SDS at CP diagnosis was +0.68 S.D. (range: -2.7 to +7.0 s.D.). The median BMI SDS at study was +3.14 s.D. (range: -0.79 to +10.90 s.D. $)(P<0.001)$. All $\mathrm{CP}$ patients underwent surgery. In $30 \mathrm{CP}$ patients (38\%), a total resection was achieved, in 43 (54\%) patients an incomplete resection, and for $6(8 \%)$ patients the degree of surgical resection was not specified. A total of 39 CP patients (49\%) presented with reference-confirmed HI and 38 (48\%) without $\mathrm{HI}$ at the time of primary diagnosis. Because of limited quality of MRI diagnostics, HI status could not be specified in two patients (3\%).

We compared characteristics of GH subgroups and observed no differences with regard to gender, age at diagnosis, symptoms in patient history and follow-up period. Tumor size, location and HI were similar in each subgroup. No differences between GH subgroups were detectable in terms of degree of surgical resection and the rate of performed radio oncological treatments (external photon irradiation, median dose: 54 Gy) (Table 1 ).

OS rates were similar for all analyzed subgroups. Two fatal events occurred, one in the nonGH and one in the contGH subgroup. In 65 of $79 \mathrm{CP}$ patients, data for estimation of PFS by Kaplan-Meier analyses were available. PFS rates were comparable between the contGH, pedGH, adultGH, noGH patient subgroups $(P=0.0893)$ (Fig. 1$)$.

\section{Height development}

We compared height development in our GH subgroups for the time points (a) at the time of CP diagnosis, (b) during 8-12 years of follow-up and (c) after $>12$ year follow-up after CP diagnosis. Patients substituted with GH during growth phase (contGH and pedGH subgroups) presented with significant increases in height SDS (contGH: $P=0.002$; pedGH: $P=0.0001$ ) during long-term follow-up when compared with height at diagnosis. In patients without GH substitution (noGH) 


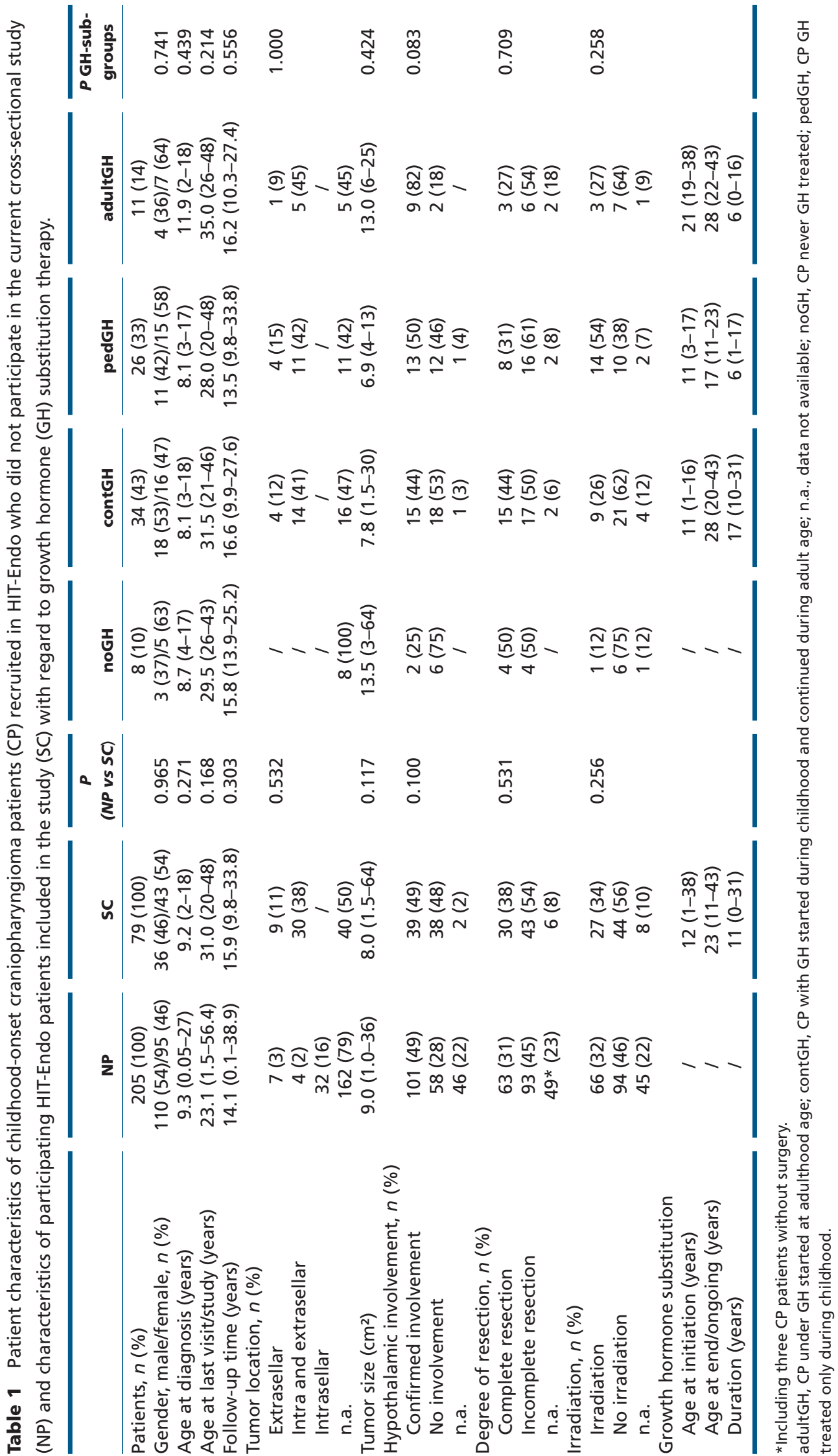




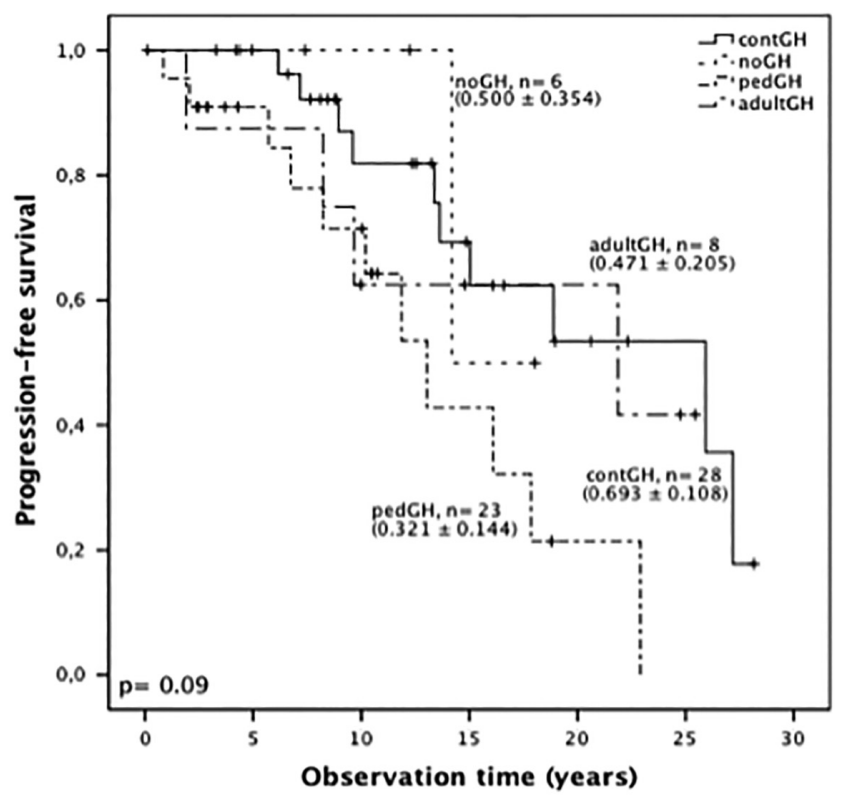

Figure 1

Kaplan-Meier analysis of progression-free survival (PFS) of patients with childhood-onset craniopharyngioma (CP) recruited in HIT-Endo with regard to growth hormone (GH) substitution therapy. noGH, CP never GH-treated; pedGH, CP $\mathrm{GH}$-treated only during childhood; adultGH, $\mathrm{CP}$ under $\mathrm{GH}$ started at adulthood age; contGH, CP with GH started during childhood and continued during adult age.

and patients treated only at adult age (adultGH), longterm increases of height SDS were not detectable when compared with respective height SDS at the time of CP diagnosis (Fig. 2).

\section{Weight development}

We compared weight development in our GH subgroups for the time points (a) at CP diagnosis, (b) during 8-12 years of follow-up and (c) after >12-year follow-up after CP diagnosis. BMI SDS was similar at CP diagnosis for all GH subgroups. At the time of the study, in all patient subgroups except for the pedGH subgroup, significant increases in BMI SDS were detectable when compared with BMI SDS at time of CP diagnosis. However, it has to be pointed out that patients with $\mathrm{GH}$ substitution during childhood continuing at adult age (contGH) also experienced significant increases in BMI SDS between the time of CP diagnosis and 8-12 years of follow-up $(P=0.01)$ and $>12$-year follow-up $(P=0.001)$. Differences between BMI SDS at 8-12 years of follow-up vs $>12$-year follow-up were not observed in any of the subgroups (Fig. 3). Long-term BMI SDS at >12-year

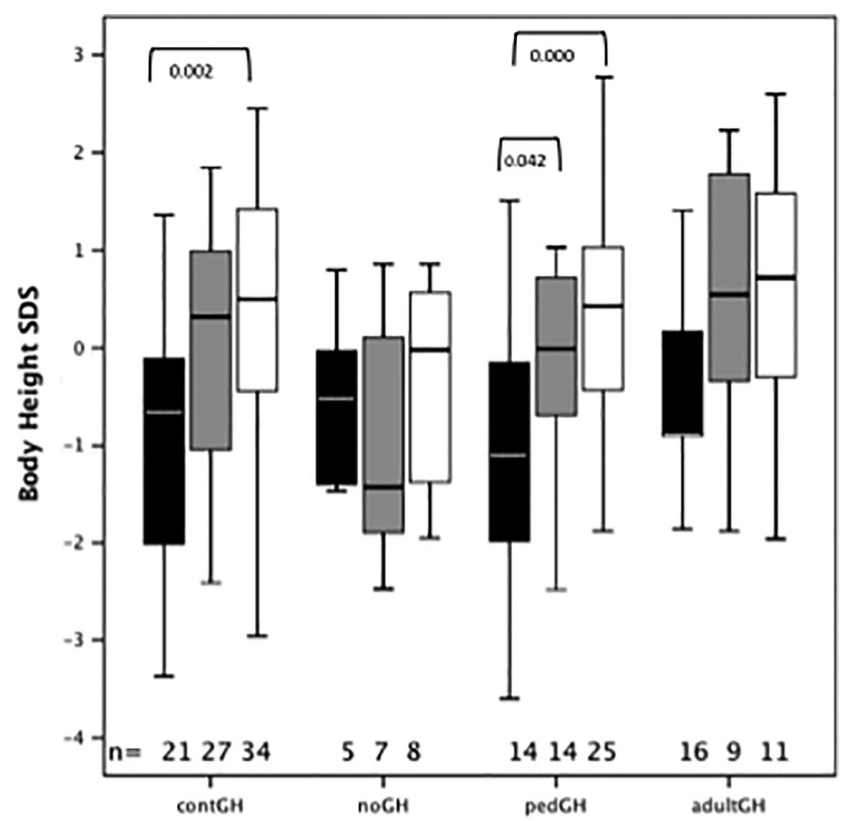

Figure 2

Height development in childhood-onset craniopharyngioma patients $(\mathrm{CP})$ recruited in HIT-Endo with regard to growth hormone $(\mathrm{GH})$ substitution therapy. noGH, CP never $\mathrm{GH}$-treated; pedGH, CP GH-treated only during childhood; adultGH, $\mathrm{CP}$ under $\mathrm{GH}$ started at adulthood age; contGH, CP with $\mathrm{GH}$ started during childhood and continued during adult age. Height SDS (17) is shown at time of diagnosis and at two intervals after diagnosis (8-12 years and $>12$ years). Black boxes: height SDS at diagnosis; gray boxes: height SDS at 8-12 years follow-up; white boxes: height SDS at $>12$ years follow-up. The horizontal line in the middle of the box depicts the median. The top and bottom edges of the box respectively mark the 25 th and 75 th percentiles.

Whiskers indicate the range of values that fall within 1.5 box-lengths.

follow-up reached similar high plateaus when compared between subgroups $(P=0.087)$.

\section{Neuropsychological status and QoS}

QoS and neuropsychological status were assessed $>10$ years after CP diagnosis using EORTC QLQ-C30 and MFI20 questionnaires in $77 \mathrm{CP}$ patients. Analyzing EORTC QLQ-C30 functioning domains, differences between $\mathrm{GH}$ subgroups were detectable only in terms of emotional functioning (Fig. 4A). AdultGH CP patients presented with a worse response $(P=0.037)$ in this domain (mean percentage: 61.4\%) when compared with pedGH CP patients (mean percentage: 83.5\%). For EORTC QLQ-C30 


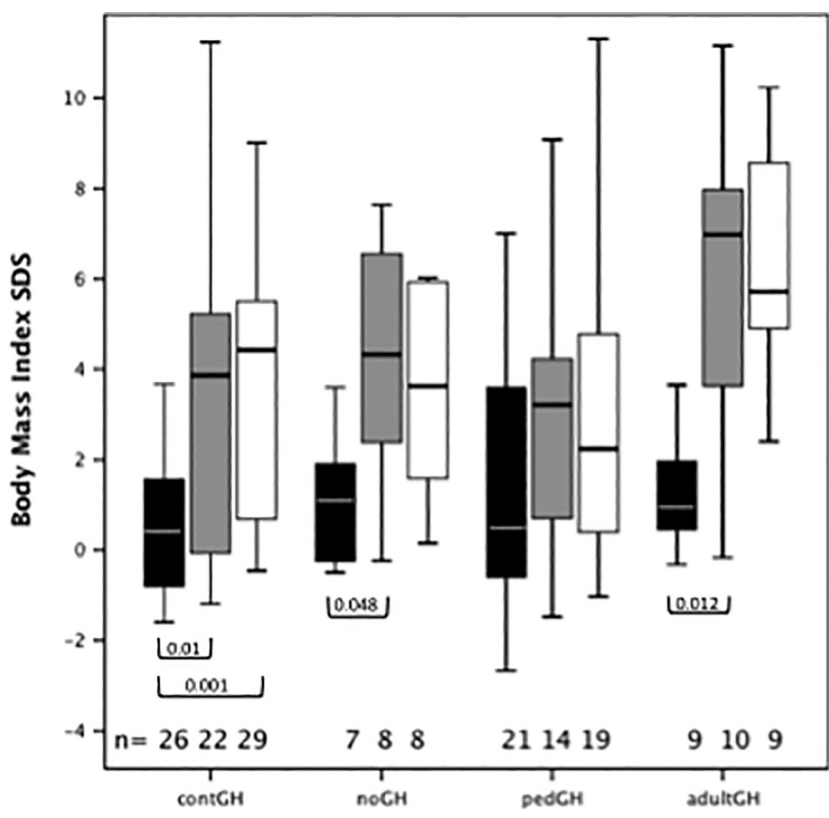

Figure 3

Weight development in childhood-onset craniopharyngioma patients $(\mathrm{CP})$ recruited in HIT-Endo with regard to growth hormone (GH) substitution therapy. noGH, CP never GH treated; pedGH, $\mathrm{CP}$ GH treated only during childhood; adultGH, CP under GH started at adulthood age; contGH, CP with $\mathrm{GH}$ started during childhood and continued during adult age. BMI SDS (18) is shown at time of diagnosis and at two intervals after diagnosis ( $8-12$ years and $>12$ years). Black boxes: BMI SDS at diagnosis; gray boxes: BMI SDS at 8-12 years follow-up; white boxes: BMI SDS at $>12$ years follow-up. The horizontal line in the middle of the box depicts the median. The top and bottom edges of the box respectively mark the 25th and 75th percentiles. Whiskers indicate the range of values that fall within 1.5 box-lengths.

symptom scales, no differences were detectable between GH subgroups (Fig. 4B).

In the MFI-20 questionnaire, $\mathrm{CP}$ patients of the adultGH subgroup were observed with a higher score in the domain physical fatigue (mean score: 12.5) when compared with pedGH CP patients (mean score: 7.7) (Fig. 4C). Differences between GH subgroups with regard to the other MFI-20 domains (general fatigue, reduced activity, reduced motivation and mental fatigue) did not reach statistical significance.

Furthermore, we compared neuropsychological status, QoS and fatigue between $27 \mathrm{CP}$ patients who were treated with external photon irradiation (XRT) and 42 non-irradiated CP patients. Differences between irradiated and non-irradiated $\mathrm{CP}$ patients were not detectable for
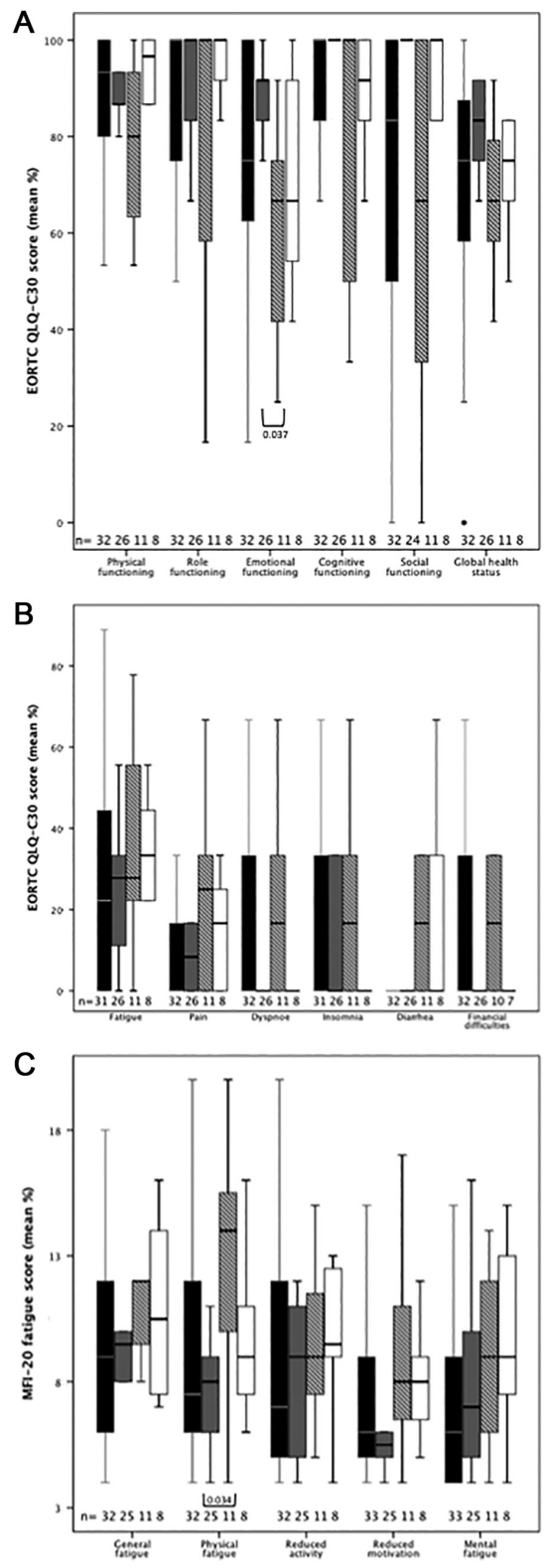

Figure 4

EORTC QLQ-C30 functioning domains (A) and symptom scales (B) and MFI-20 fatigue domains (C) in childhood-onset craniopharyngioma patients (CP) recruited in HIT-Endo with regard to growth hormone (GH) substitution therapy. Black boxes: $\mathrm{CP}$ with $\mathrm{GH}$ started during childhood and continued during adult age (contGH); dark grey boxes: CP patients $\mathrm{GH}$-treated only during childhood (pedGH); hatched boxes: $\mathrm{CP}$ under $\mathrm{GH}$ started at adulthood age (adultGH); white boxes: $\mathrm{CP}$ patients never GH-treated (noGH). The horizontal line in the middle of the box depicts the median. The top and bottom edges of the box respectively mark the 25th and 75th percentiles. Whiskers indicate the range of values that fall within 1.5 box-lengths. 
any of the EORTC QLQ-C30 and MFI-20 domains (data not shown).

\section{Psychosocial status}

To assess previously not analyzed long-term outcome in CP patients, we evaluated psychosocial status with regard to parameters such as married/partner, offspring, employment, professional education and having a driver license in adult CP patients (age at study $>20$ years). Only 2 of the 79 adult CP patients (2.5\%) reported having (healthy) offspring. These two CP patients belonged to the contGH subgroup. However, no differences between GH subgroups could be detected for all parameters assessed in the psychosocial questionnaire (Table 2).

\section{Discussion}

Overall survival after childhood-onset CP is high. The 10 -year survival rates range from 62 to $100 \%$ after radical complete surgical resection $(10,21,22,23,24,25,26$, $27), 27-86 \%$ after incomplete surgical resection (10, $21,22,23,24,25), 74-100 \%$ after incomplete surgical resection followed by irradiation $(21,25)$ and $81-100 \%$ after radiooncological treatment alone $(26,27)$. Adultonset CP patients are reported to have up to fivefold higher mortality and morbidity rates when compared to general population $(28,29)$ and to patient cohorts with different origin of pituitary insufficiency. Many published reports on long-term follow-up after childhood-onset $\mathrm{CP}$ are focused on survival rates and lack information on specific sequelae $(22,25,26,27,30)$. However, QoS is frequently impaired in the pediatric age group due to treatment and/or disease-associated factors such as HI, neuropsychological $(31,32)$ and neuroendocrine deficits $(16,21,33,34,35,36,37,38,39,40,41,42)$ including $\mathrm{GH}$ deficiency being the most frequent pituitary deficiency (54-100\%) (1, 37, 39).

Our study is the first report in the literature, which analyzed not only long-term survival but also psychosocial status and QoS with special regard to timing and duration of $\mathrm{GH}$ substitution therapy. In our study cohort, we observed an OS rate $100 \%$ as no fatal events occurred. We have previously reported on impairments in terms of psychosocial status, such as living in partner relationship/ marriage, having offspring and holding of a driver license, as well as severe QoS-compromising sequeale such as reduced motivation and physical functioning in longterm survivors of childhood-onset CP with HI. Physical fatigue, obesity, dyspnea and diarrhea were major sequelae in these patients. However, associations with $\mathrm{GH}$ substitution were not analyzed in that study (10).

It is well known that GH substitution therapy improves growth in childhood-onset CP patients (43, 44 , 45). However, long-term effects of GH substitution therapy on height, weight, QoS and psychosocial status have not been investigated prospectively in childhoodonset CP patients. Accordingly, we analyzed for CP patients recruited before 2000 and observed prospectively in the HIT-Endo trial whether (1) GH substitution therapy was associated with changes in height, BMI, QoS and psychosocial and neuropsychological status during longterm follow-up of $>10$ years after CP diagnosis and (2) whether these changes were related to age at initiation and duration of GH substitution therapy.

Differences between the analyzed subgroups of GH-substituted and non-substituted CP patients with regard to age at CP diagnosis and study, gender, follow-up interval, tumor location and size, HI, degree of surgical resection and irradiation were not detectable (Table 1). Our results support previous findings (11) that GH substitution was not associated with decreased OS and EFS rates. However, it has to be pointed out that regardless of

Table 2 Psychosocial status of childhood-onset craniopharyngioma patients (CP) recruited in HIT-Endo with regard to growth hormone (GH) substitution therapy. Data are presented as $n(\%)$.

\begin{tabular}{lcc}
\hline$n$ & & Total \\
\cline { 3 - 3 } Married/partner & & $79(13.9)$ \\
Children/pregnant & & $2(2.5)$ \\
Social functionality/friends & & $50(63.3)$ \\
Professional education & & $38(48.1)$ \\
Employed & $52(65.8)$ \\
Driver's license & $42(53.2)$ \\
Psychological treatment & $33(41.8)$ \\
\hline
\end{tabular}

\begin{tabular}{c}
\hline nOGH \\
\hline 8 \\
$1(12.5)$ \\
$0(0.0)$ \\
$4(50.0)$ \\
$3(37.5)$ \\
$5(62.5)$ \\
$4(50.0)$ \\
$4(50.0)$ \\
\hline
\end{tabular}

\begin{tabular}{c}
\hline contGH \\
\hline 34 \\
$4(11.8)$ \\
$2(5.9)$ \\
$21(61.8)$ \\
$18(53.0)$ \\
$20(58.8)$ \\
$17(50.0)$ \\
$13(38.2)$ \\
\hline
\end{tabular}

\begin{tabular}{c}
\hline pedGH \\
\hline 26 \\
$5(19.2)$ \\
$0(0.0)$ \\
$17(65.4)$ \\
$14(53.8)$ \\
$21(80.8)$ \\
$14(53.8)$ \\
$14(53.8)$ \\
\hline
\end{tabular}

\begin{tabular}{c}
\hline adultGH \\
\hline 11 \\
$1(9.1)$ \\
$0(0.0)$ \\
$8(72.7)$ \\
$3(27.3)$ \\
$6(54.5)$ \\
$7(63.6)$ \\
$2(18.2)$ \\
\hline
\end{tabular}

\begin{tabular}{c}
\hline $\boldsymbol{P}$ \\
\hline \\
0.857 \\
0.713 \\
0.766 \\
0.442 \\
0.251 \\
0.886 \\
0.219 \\
\hline
\end{tabular}

adultGH, $\mathrm{CP}$ under $\mathrm{GH}$ started at adulthood age; contGH, $\mathrm{CP}$ with $\mathrm{GH}$ started during childhood and continued during adult age; noGH, $\mathrm{CP}$ never $\mathrm{GH}$ treated; pedGH, $\mathrm{CP}$ GH treated only during childhood. 
GH substitution frequent events in terms of progression and relapses occurred during long-term follow-up in all analyzed subgroups $(11,46)$.

We recently reported on short-term effects of GH substitution on growth during the first 3 years after $\mathrm{CP}$ diagnosis (6). Whereas significant improvements of growth could not be observed under GH substitution therapy at 3 years after CP diagnosis (6), in this study, we report on significantly improved growth in all GH-substituted subgroups (contGH and pedGH). Non-GH-substituted patients and CP patients with GH substitution confined to adult age (adultGH) presented with similar height SD at diagnosis and during long-term follow-up.

Severe hypothalamic obesity is a major welldescribed sequelae after childhood-onset $\mathrm{CP}$, occurring in $40-66 \%$ of CP patients $(47,48)$. Hypothalamic obesity represents a significant risk factor for chronic diseases resulting in increased risk for cardiovascular disease and metabolic syndrome $(49,50)$. HI and/or treatmentrelated hypothalamic lesions are major risk factors for the development of hypothalamic syndrome $(16,51,52)$. Especially long-term CP survivors with hypothalamic lesions present with morbidity including severe obesity and impaired QoS $(15,36,37,38,39,40,41,49,53)$. Previous follow-up studies reported on the prevalence of hypothalamic obesity but did not include detailed analyses of weight development during long-term follow-up (25, $28,54)$. In the present study, we analyzed BMI SDS after follow-up of $>12$ years. The rate of $\mathrm{HI}$ and the degree of treatment-related hypothalamic damage were similar in all analyzed subgroups. Significant weight gain resulting in obesity was observed in all patient subgroups. We also could demonstrate for all subgroups that no further BMI SDS increase could be observed after $>12$ years of follow-up.

Several studies $(45,55,56,57,58)$ report on protective effects of GH substitution therapy on body composition and weight development in adult-onset CP survivors. However, similar to previous reports in our study GH substitution did not prevent the development of severe obesity after childhood-onset CP. However, it should be pointed out, that in our pedGH subgroup increases in BMI SDS during follow-up did not reach statistical significance. Using the least invasive, hypothalamussparing surgical techniques is currently considered to be the most appropriate option to handle hypothalamic obesity, since effective treatment of hypothalamic obesity is still not available.

Childhood patients treated early on with GH (pedGH) presented with an overall better long-term outcome in terms of height, weight and neuropsychological findings when compared with patients in whom GH substitution was initiated later on during adulthood (adultGH) or patients who did not receive any GH substitution at all (noGH). Patients of the pedGH subgroup developed no relevant BMI SDS increase when compared with all other subgroups. Interestingly, this observation is not supported by our findings in the subgroup receiving GH substitution during childhood and adult age (contGH). We speculate that GH substitution was continued in this subgroup due to persisting problems concerning previous weight gain. Furthermore, pedGH patients showed better scores for emotional functioning and a lower level of physical fatigue when compared with GH patients with adult-onset GH substitution. This might indicate that early onset of GH substitution after CP diagnosis provides advantages in terms of follow-up prognosis. Furthermore, diarrhea and pulmonary complaints observed as major long-term sequelae after $\mathrm{CP}$ by Sterkenburg et al. (10) were no predominant findings in any of our GH subgroups.

Due to retrospective analysis, the results of our study are limited. Some observations are speculative at this point. The decision on indication and time of initiation of GH substitution was made by treating physicians and not based on randomization. A specific grading of $\mathrm{HI}$ as performed in recent prospective studies $(15,59,60)$ was not possible due to missing data and minor quality of neuroradiological imaging in our retrospective analysis. We have chosen to express BMI SDS according to standards reported by Rolland-Cachera et al. (18) because these allow the calculation of BMI SDS for a wide age range from early childhood to adult age. A further limitation of our study is the lack of specific data on body composition. We were not able to analyze fat mass and lean mass by dualenergy X-ray absorptiometry (DEXA) or other comparable techniques. These parameters on body composition will be part of future planned studies on this cohort of longterm CP survivors.

We conclude that GH substitution was safe with regard to long-term risk of tumor progression and relapse in $\mathrm{CP}$ patients. Growth was improved by $\mathrm{GH}$ substitution, whereas weight development leading to severe obesity was not influenced by GH substitution. Early initiation of GH substitution after CP diagnosis might have beneficial effects on weight development and neuropsychological outcome.

\section{Declaration of interest}

The authors declare that there is no conflict of interest that could be perceived as prejudicing the impartiality of this study. 


\section{Funding}

This study was funded by a grant (H L M; DKS2014.13) of the German Childhood Cancer Foundation, Bonn, Germany. The publication resulted from collaboration (A B) made possible through the Merck sponsored educational programme 'ESPE Clinical Fellowship'.

\section{Author contribution statement}

$S \mathrm{~B}$ researched the data and wrote the manuscript. A B participated in data analyses and reviewed/edited the manuscript. A S S conducted and supervised multicenter data collecting and reviewed/edited the manuscript. M E did statistical analyses and discussion and reviewed/edited the manuscript. H L M initiated and conducted the multicenter trials HITEndo and KRANIOPHARYNGEOM 2000/2007, contributed to the analytical plan and discussion and reviewed/edited the manuscript.

\section{Acknowledgements}

The authors want to thank all participating colleagues for recruiting patients in Hit-Endo, and the patients and their parents for participating in this study.

\section{References}

1 Muller HL, Merchant TE, Puget S \& Martinez-Barbera JP. New outlook on the diagnosis, treatment and follow-up of childhood-onset craniopharyngioma. Nature Reviews Endocrinology 201713 299-312. (https://doi.org/10.1038/nrendo.2016.217)

2 Muller HL. Childhood craniopharyngioma - current concepts in diagnosis, therapy and follow-up. Nature Reviews Endocrinology 2010 6 609-618. (https://doi.org/10.1038/nrendo.2010.168)

3 Muller HL. Consequences of craniopharyngioma surgery in children. Journal of Clinical Endocrinology and Metabolism 201196 1981-1991. (https://doi.org/10.1210/jc.2011-0174)

4 Muller HL. Craniopharyngioma. Endocrine Reviews 201435 513-543. (https://doi.org/10.1210/er.2013-1115)

5 Muller HL, Emser A, Faldum A, Bruhnken G, Etavard-Gorris N, Gebhardt U, Oeverink R, Kolb R \& Sorensen N. Longitudinal study on growth and body mass index before and after diagnosis of childhood craniopharyngioma. Journal of Clinical Endocrinology and Metabolism 200489 3298-3305. (https://doi.org/10.1210/jc.2003-031751)

6 Heinks K, Boekhoff S, Hoffmann A, Warmuth-Metz M, Eveslage M, Peng J, Calaminus G \& Muller HL. Quality of life and growth after childhood craniopharyngioma: results of the multinational trial KRANIOPHARYNGEOM 2007. Endocrine 201859 364-372. (https:// doi.org/10.1007/s12020-017-1489-9)

7 de Vile CJ, Grant DB, Hayward RD, Kendall BE, Neville BG \& Stanhope R. Obesity in childhood craniopharyngioma: relation to post-operative hypothalamic damage shown by magnetic resonance imaging. Journal of Clinical Endocrinology and Metabolism 199681 2734-2737. (https://doi.org/10.1210/jcem.81.7.8675604)

8 Muller HL. Childhood craniopharyngioma. Pituitary 201316 56-67. (https://doi.org/10.1007/s11102-012-0401-0)

9 Bereket A, Kiess W, Lustig RH, Muller HL, Goldstone AP, Weiss R, Yavuz Y \& Hochberg Z. Hypothalamic obesity in children. Obesity Reviews 201213 780-798. (https://doi.org/10.1111/j.1467789X.2012.01004.x)

10 Sterkenburg AS, Hoffmann A, Gebhardt U, Warmuth-Metz M, Daubenbuchel AM \& Muller HL. Survival, hypothalamic obesity, and neuropsychological/psychosocial status after childhood-onset craniopharyngioma: newly reported long-term outcomes. NeuroOncology 201517 1029-1038. (https://doi.org/10.1093/neuonc/ nov044)
11 Muller HL, Gebhardt U, Schroder S, Pohl F, Kortmann RD, Faldum A, Zwiener I, Warmuth-Metz M, Pietsch T, Calaminus G et al. Analyses of treatment variables for patients with childhood craniopharyngioma - results of the multicenter prospective trial KRANIOPHARYNGEOM 2000 after three years of follow-up. Hormone Research in Paediatrics 201073 175-180. (https://doi. org/10.1159/000284358)

12 Ergun-Longmire B, Mertens AC, Mitby P, Qin J, Heller G, Shi W, Yasui Y, Robison LL \& Sklar CA. Growth Hormone treatment and risk of second neoplasms in the childhood cancer survivor. Journal of Clinical Endocrinology and Metabolism 200691 3494-3498. (https:// doi.org/10.1210/jc.2006-0656)

13 Chaplin JE, Kristrom B, Jonsson B, Hagglof B, Tuvemo T, Aronson AS, Dahlgren J \& Albertsson-Wikland K. Improvements in behaviour and self-esteem following Growth Hormone treatment in short prepubertal children. Hormone Research in Paediatrics 201175 291-303. (https://doi.org/10.1159/000322937)

14 Smith TR, Cote DJ, Jane JA Jr \& Laws ER. Physiological growth hormone replacement and rate of recurrence of craniopharyngioma: the Genentech National Cooperative Growth Study. Journal of Neurosurgery: Pediatrics 201618 408-412. (https://doi.org/10.3171/20 16.4.PEDS16112)

15 Muller HL, Gebhardt U, Teske C, Faldum A, Zwiener I, WarmuthMetz M, Pietsch T, Pohl F, Sorensen N, Calaminus G et al. Post-operative hypothalamic lesions and obesity in childhood craniopharyngioma: results of the multinational prospective trial KRANIOPHARYNGEOM 2000 after 3-year follow-up. European Journal of Endocrinology 2011165 17-24. (https://doi.org/10.1530/ EJE-11-0158)

16 Muller HL, Bueb K, Bartels U, Roth C, Harz K, Graf N, Korinthenberg R, Bettendorf M, Kuhl J, Gutjahr P et al. Obesity after childhood craniopharyngioma - German multicenter study on preoperative risk factors and quality of life. Klinische Padiatrie $20012 \mathbf{2 1 3}$ 244-249. (https://doi.org/10.1055/s-2001-16855)

17 Prader A, Largo RH, Molinari L \& Issler C. Physical growth of Swiss children from birth to 20 years of age. First Zurich longitudinal study of growth and development. Helvetica Paediatrica Acta: Supplementum $1989521-125$.

18 Rolland-Cachera MF, Cole TJ, Sempe M, Tichet J, Rossignol C \& Charraud A. Body mass index variations: centiles from birth to 87 years. European Journal of Clinical Nutrition 199145 13-21.

19 Aaronson NK, Ahmedzai S, Bergman B, Bullinger M, Cull A, Duez NJ, Filiberti A, Flechtner H, Fleishman SB \& de Haes JC. The European Organization for Research and Treatment of Cancer QLQ-C30: a quality-of-life instrument for use in international clinical trials in oncology. Journal of the National Cancer Institute 199385 365-376. (https://doi.org/10.1093/jnci/85.5.365)

20 Smets EM, Garssen B, Bonke B \& De Haes JC. The Multidimensional Fatigue Inventory (MFI) psychometric qualities of an instrument to assess fatigue. Journal of Psychosomatic Research 199539 315-325. (https://doi.org/10.1016/0022-3999(94)00125-O)

21 Karavitaki N, Brufani C, Warner JT, Adams CB, Richards P, Ansorge O, Shine B, Turner HE \& Wass JA. Craniopharyngiomas in children and adults: systematic analysis of 121 cases with long-term follow-up. Clinical Endocrinology 200562 397-409. (https://doi.org/10.1111/ j.1365-2265.2005.02231.x)

22 Van Effenterre R \& Boch AL. Craniopharyngioma in adults and children: a study of 122 surgical cases. Journal of Neurological Surgery 200297 3-11. (https://doi.org/10.3171/jns.2002.97.1.0003)

23 Mortini P, Losa M, Pozzobon G, Barzaghi R, Riva M, Acerno S, Angius D, Weber G, Chiumello G \& Giovanelli M. Neurosurgical treatment of craniopharyngioma in adults and children: early and long-term results in a large case series. Journal of Neurological Surgery 2011114 1350-1359. (https://doi.org/10.3171/2010.11.JNS10670)

24 Rao YJ, Hassanzadeh C, Fischer-Valuck B, Chicoine MR, Kim AH, Perkins SM \& Huang J. Patterns of care and treatment outcomes 
of patients with craniopharyngioma in the national cancer database. Journal of Neuro-Oncology 2017132 109-117. (https://doi. org/10.1007/s11060-016-2342-3)

25 Stripp DC, Maity A, Janss AJ, Belasco JB, Tochner ZA, Goldwein JW, Moshang T, Rorke LB, Phillips PC, Sutton LN et al. Surgery with or without radiation therapy in the management of craniopharyngiomas in children and young adults. International Journal of Radiation Oncology, Biology, Physics 200458 714-720. (https://doi.org/10.1016/S0360-3016(03)01570-0)

26 Scott RM, Hetelekidis S, Barnes PD, Goumnerova L \& Tarbell NJ. Surgery, radiation, and combination therapy in the treatment of childhood craniopharyngioma - a 20-year experience. Pediatric Neurosurgery 199421 (Supplement 1) 75-81. (https://doi. org/10.1159/000120866)

27 Hetelekidis S, Barnes PD, Tao ML, Fischer EG, Schneider L, Scott RM \& Tarbell NJ. 20-year experience in childhood craniopharyngioma. International Journal of Radiation Oncology, Biology, Physics 199327 189-195. (https://doi.org/10.1016/03603016(93)90227-M)

28 Pereira AM, Schmid EM, Schutte PJ, Voormolen JH, Biermasz NR, van Thiel SW, Corssmit EP, Smit JW, Roelfsema F \& Romijn JA. High prevalence of long-term cardiovascular, neurological and psychosocial morbidity after treatment for craniopharyngioma. Clinical Endocrinology 200562 197-204. (https://doi.org/10.1111/ j.1365-2265.2004.02196.x)

29 Bulow B, Attewell R, Hagmar L, Malmstrom P, Nordstrom CH \& Erfurth EM. Postoperative prognosis in craniopharyngioma with respect to cardiovascular mortality, survival, and tumor recurrence. Journal of Clinical Endocrinology and Metabolism 199883 3897-3904. (https://doi.org/10.1210/jcem.83.11.5240)

30 Winkfield KM, Tsai HK, Yao X, Larson E, Neuberg D, Pomeroy SL, Ullrich NJ, Cohen LE, Kieran MW, Scott RM et al. Long-term clinical outcomes following treatment of childhood craniopharyngioma. Pediatric Blood and Cancer 201156 1120-1126. (https://doi. org $/ 10.1002 /$ pbc.22884)

31 Ozyurt J, Thiel CM, Lorenzen A, Gebhardt U, Calaminus G, Warmuth-Metz M \& Muller HL. Neuropsychological outcome in patients with childhood craniopharyngioma and hypothalamic involvement. Jurnalul Pediatrului 2014164 876.e874-881.e874. (https://doi.org/10.1016/j.jpeds.2013.12.010)

32 Mehren A, Ozyurt J, Zu Klampen P, Boekhoff S, Thiel CM \& Muller HL. Self- and informant-rated apathy in patients with childhood-onset craniopharyngioma. Journal of Neuro-Oncology 2018 Epub. (https://doi.org/10.1007/s11060-018-2936-z)

33 Kendall-Taylor P, Jonsson PJ, Abs R, Erfurth EM, KoltowskaHaggstrom M, Price DA \& Verhelst J. The clinical, metabolic and endocrine features and the quality of life in adults with childhood-onset craniopharyngioma compared with adult-onset craniopharyngioma. European Journal of Endocrinology 2005152 557-567. (https://doi.org/10.1530/eje.1.01877)

34 Merchant TE, Kiehna EN, Sanford RA, Mulhern RK, Thompson SJ, Wilson MW, Lustig RH \& Kun LE. Craniopharyngioma: the St. Jude Children's Research Hospital experience 1984-2001. International Journal of Radiation Oncology, Biology, Physics 200253 533-542. (https://doi.org/10.1016/S0360-3016(02)02799-2)

35 Lo AC, Howard AF, Nichol A, Sidhu K, Abdulsatar F, Hasan H \& Goddard K. Long-term outcomes and complications in patients with craniopharyngioma: the British Columbia Cancer Agency experience. International Journal of Radiation Oncology, Biology, Physics $2014 \mathbf{8 8}$ 1011-1018. (https://doi.org/10.1016/j.ijrobp.2014.01.019)

36 Gautier A, Godbout A, Grosheny C, Tejedor I, Coudert M, Courtillot C, Jublanc C, De Kerdanet M, Poirier JY, Riffaud L et al. Markers of recurrence and long-term morbidity in craniopharyngioma: a systematic analysis of 171 patients. Journal of Clinical Endocrinology and Metabolism 201297 1258-1267. (https:// doi.org/10.1210/jc.2011-2817)
37 Tan TS, Patel L, Gopal-Kothandapani JS, Ehtisham S, Ikazoboh EC, Hayward R, Aquilina K, Skae M, Thorp N, Pizer B et al. The neuroendocrine sequelae of paediatric craniopharyngioma: a 40-year meta-data analysis of 185 cases from three UK centres. European Journal of Endocrinology 2017176 359-369. (https://doi.org/10.1530/ EJE-16-0812)

38 Olsson DS, Andersson E, Bryngelsson IL, Nilsson AG \& Johannsson G. Excess mortality and morbidity in patients with craniopharyngioma, especially in patients with childhood onset: a population-based study in Sweden. Journal of Clinical Endocrinology and Metabolism 2015100 467-474. (https://doi.org/10.1210/ jc.2014-3525)

39 Wijnen M, van den Heuvel-Eibrink MM, Janssen J, CatsmanBerrevoets CE, Michiels EMC, van Veelen-Vincent MC, Dallenga AHG, van den Berge JH, van Rij CM, van der Lely AJ et al. Very long-term sequelae of craniopharyngioma. European Journal of Endocrinology 2017176 755-767. (https://doi.org/10.1530/EJE-170044)

40 Wijnen M, Olsson DS, van den Heuvel-Eibrink MM, Hammarstrand C, Janssen J, van der Lely AJ, Johannsson G \& Neggers S. The metabolic syndrome and its components in 178 patients treated for craniopharyngioma after 16 years of follow-up. European Journal of Endocrinology 2018178 11-22. (https://doi. org/10.1530/EJE-17-0387)

41 Wijnen M, Olsson DS, van den Heuvel-Eibrink MM, Hammarstrand C, Janssen J, van der Lely AJ, Johannsson G $\&$ Neggers S. Excess morbidity and mortality in patients with craniopharyngioma: a hospital-based retrospective cohort study. European Journal of Endocrinology 2018178 95-104. (https://doi. org/10.1530/EJE-17-0707)

42 Muller H. Craniopharyngioma - a chronic disease. Swiss Medical Weekly 2018148 w14548. (https://doi.org/10.4414/smw.2018.14548)

43 Gleeson HK, Stoeter R, Ogilvy-Stuart AL, Gattamaneni HR, Brennan BM \& Shalet SM. Improvements in final height over 25 years in Growth Hormone (GH)-deficient childhood survivors of brain tumors receiving GH replacement. Journal of Clinical Endocrinology and Metabolism 200388 3682-3689. (https://doi. org/10.1210/jc.2003-030366)

44 Price DA, Wilton P, Jonsson P, Albertsson-Wikland K, Chatelain P, Cutfield W \& Ranke MB. Efficacy and safety of Growth Hormone treatment in children with prior craniopharyngioma: an analysis of the Pharmacia and Upjohn International Growth Database (KIGS) from 1988 to 1996. Hormone Research 199849 91-97. (https://doi. org/10.1159/000023133)

45 Yuen KC, Koltowska-Haggstrom M, Cook DM, Fox JL, Jonsson PJ, Geffner ME \& Abs R. Clinical characteristics and effects of GH replacement therapy in adults with childhood-onset craniopharyngioma compared with those in adults with other causes of childhood-onset hypothalamic-pituitary dysfunction. European Journal of Endocrinology 2013169 511-519. (https://doi.org/10.1530/ EJE-13-0280)

46 Muller HL, Gebhardt U, Pohl F, Flentje M, Emser A, WarmuthMetz M, Kolb R, Calaminus G \& Sorensen N. Relapse pattern after complete resection and early progression after incomplete resection of childhood craniopharyngioma. Klinische Padiatrie 2006218 315-320. (https://doi.org/10.1055/s-2006-942249)

47 Crom DB, Smith D, Xiong Z, Onar A, Hudson MM, Merchant TE \& Morris EB. Health status in long-term survivors of pediatric craniopharyngiomas. Journal of Neuroscience Nursing 201042 323-328; quiz 329-330. (https://doi.org/10.1097/ JNN.0b013e3181f8a59d)

48 Muller HL, Faldum A, Etavard-Gorris N, Gebhardt U, Oeverink R, Kolb R \& Sorensen N. Functional capacity, obesity and hypothalamic involvement: cross-sectional study on 212 patients with childhood craniopharyngioma. Klinische Padiatrie 2003215 310-314. (https:// doi.org/10.1055/s-2003-45499) 
49 Holmer H, Ekman B, Bjork J, Nordstom CH, Popovic V, Siversson A \& Erfurth EM. Hypothalamic involvement predicts cardiovascular risk in adults with childhood onset craniopharyngioma on long-term GH therapy. European Journal of Endocrinology 2009161 671-679. (https://doi.org/10.1530/EJE-09-0449)

50 Srinivasan S, Ogle GD, Garnett SP, Briody JN, Lee JW \& Cowell CT. Features of the metabolic syndrome after childhood craniopharyngioma. Journal of Clinical Endocrinology and Metabolism 200489 81-86. (https://doi.org/10.1210/jc.2003-030442)

51 Poretti A, Grotzer MA, Ribi K, Schonle E \& Boltshauser E. Outcome of craniopharyngioma in children: long-term complications and quality of life. Developmental Medicine and Child Neurology 200446 220-229. (https://doi.org/10.1111/j.1469-8749.2004.tb00476.x)

52 Lustig RH. Hypothalamic obesity: causes, consequences, treatment. Pediatric Endocrinology Reviews 20086 220-227.

53 Hoffmann A, Postma FP, Sterkenburg AS, Gebhardt U \& Muller HL. Eating behavior, weight problems and eating disorders in 101 longterm survivors of childhood-onset craniopharyngioma. Journal of Pediatric Endocrinology and Metabolism 201528 35-43. (https://doi. org/10.1515/jpem-2014-0415)

54 Tomita T \& Bowman RM. Craniopharyngiomas in children: surgical experience at Children's Memorial Hospital. Child's Nervous System 200521 729-746. (https://doi.org/10.1007/s00381005-1202-9)

55 Yuen KCJ, Mattsson AF, Burman P, Erfurth EM, CamachoHubner C, Fox JL, Verhelst J, Geffner ME \& Abs R. Relative risks of contributing factors to morbidity and mortality in adults with craniopharyngioma on Growth Hormone replacement. Journal of Clinical Endocrinology and Metabolism 2018103 768-777. (https:// doi.org/10.1210/jc.2017-01542)
56 Gotherstrom G, Svensson J, Koranyi J, Alpsten M, Bosaeus I, Bengtsson B \& Johannsson G. A prospective study of 5 years of GH replacement therapy in GH-deficient adults: sustained effects on body composition, bone mass, and metabolic indices. Journal of Clinical Endocrinology and Metabolism 200186 4657-4665. (https:// doi.org/10.1210/jcem.86.10.7887)

57 Koranyi J, Svensson J, Gotherstrom G, Sunnerhagen KS, Bengtsson B \& Johannsson G. Baseline characteristics and the effects of five years of GH replacement therapy in adults with GH deficiency of childhood or adulthood onset: a comparative, prospective study. Journal of Clinical Endocrinology and Metabolism 200186 4693-4699. (https://doi.org/10.1210/jcem.86.10.7896)

58 Attanasio AF, Bates PC, Ho KK, Webb SM, Ross RJ, Strasburger CJ, Bouillon R, Crowe B, Selander K, Valle D et al. Human growth hormone replacement in adult hypopituitary patients: long-term effects on body composition and lipid status - 3-year results from the HypoCCS Database. Journal of Clinical Endocrinology and Metabolism 200287 1600-1606. (https://doi.org/10.1210/jcem.87.4.8429)

59 Muller HL, Gebhardt U, Faldum A, Warmuth-Metz M, Pietsch T, Pohl F, Calaminus G, Sorensen N \& Kraniopharyngeom 2000 Study Committee. Xanthogranuloma, Rathke's cyst, and childhood craniopharyngioma: results of prospective multinational studies of children and adolescents with rare sellar malformations. Journal of Clinical Endocrinology and Metabolism 201297 3935-3943. (https:// doi.org/10.1210/jc.2012-2069)

60 Hoffmann A, Warmth-Metz M, Gebhardt U, Pietsch T, Pohl F, Kortmann RD, Calaminus G \& Muller HL. Childhood craniopharyngioma - changes of treatment strategies in the trials KRANIOPHARYNGEOM 2000/2007. Klinische Padiatrie 2014226 161-168. (https://doi.org/10.1055/s-0034-1368785)

Received 19 June 2018

Revised version received 13 August 2018

Accepted 22 August 2018 